UNIVERSIDADE ESTADUAL DE FEIRA DE SANTANA

Autorizada pelo Decreto Federal $n^{\circ} 77.496$ de 27/04/76

Recredenciamento pelo Decreto $n^{\circ} 17.228$ de 25/11/2016

PRÓ-REITORIA DE PESQUISA E PÓS-GRADUAÇÃO

COORDENAÇÃO DE INICIAÇÃO CIENTÍFICA

PPPG

XXIII SEMINÁRIO DE INICIAÇÃO CIENTÍFICA DA UEFS

SEMANA NACIONAL DE CIENTÍFICA E TECNOLÓGICA - 2019

\title{
MÚSICAS INDÍGENAS: IDENTIDADES SONORAS DA RESIDÊNCIA INDÍGENA DA UNIVERSIDADE ESTADUAL DE FEIRA DE SANTANA
}

\author{
Cibelle Assis de Souza ${ }^{1}$; Cláudia Elisiane Ferreira Santos ${ }^{2}$ \\ 1. Bolsista PIBIC/FAPESB, Graduanda em Psicologia, Universidade Estadual de Feira \\ de Santana, e-mail: flechiatuxa@gmail.com \\ 2. Orientadora, Departamento de Letras e artes, Universidade Estadual de Feira de \\ Santana, e-mail: claudiaefs@gmail.com
}

PALAVRAS-CHAVE: formação docente; música indígena; residência indígena

\section{INTRODUÇÃO}

Nós, povos indígenas, somos donos de grande diversidade cultural, mas que infelizmente ainda é invisibilizada por boa parte da sociedade envolvente, que nos enxerga de forma estereotipada. Segundo dados do censo demográfico (IBGE, 2010) atualmente, há mais de 305 etnias e 274 línguas, apontando para a vasta riqueza étnico-cultural da nossa população. O Nordeste é a segunda região com maior população indígena do país com 232.739 mil habitantes (IBGE, 2010), distribuídas em diferentes etnias e aldeias. Essa diversidade reflete-se, também, na nossa presença nas universidades, que embora ainda aconteça de forma tímida, há sempre representações de diferentes povos nessas instituições. A Universidade Estadual de Feira de Santana (UEFS), implantou em 2007 a sua Política de Ações Afirmativas, que previa uma vaga para indígenas em cada curso da graduação, hoje, há aproximadamente 60 estudantes indígenas pertencentes a 9 etnias do estado da Bahia e Pernambuco, sendo elas: Tuxá (BA), Tumbalalá (BA), Truká (PE), Pataxó Hãhãhãe (BA), Pankararé (BA), Pankararu (PE), Pankará (PE), Atikum (BA) e Fulni-ô (PE).

Na UEFS, no curso de Licenciatura em Música, resultados de pesquisas realizadas no ano de 2015 "Às relações étnicas e culturais nas escolas feirenses no âmbito das práticas pedagógicas musicais", e em 2016 “A formação do licenciando em Música na perspectiva da diversidade cultural", constataram que a diversidade cultural nas práticas pedagógicas adotadas pelo Subprojeto Musicando a Escola (PIBID de Música da UEFS), era contemplada parcialmente, e quando dialogado com a Lei 11.645/2008, nas aulas de música as culturas indígenas não eram contempladas (SANTOS, 2017). Nessa perspectiva, a presente pesquisa surge a partir de três pontos fundamentais: a grande diversidade cultural dos nossos povos, refletida num ambiente pluriétnico como a Residência Indígena da UEFS; a necessidade que os licenciados de música sentem de ter materiais que auxiliem suas práticas nas aulas de música no que se refere as culturas indígenas; e a necessidade que nós, indígenas, temos de desconstruir estereótipos a partir da apresentação de elementos que correspondem as nossas realidades. Assim, considerando que as escolas são espaços importantes para promover essas trocas de conhecimentos, a pesquisa surge com o objetivo de coletar e registrar 
cantos/toantes/linhas/toré dos povos indígenas que estão representados por seus estudantes na UEFS, pensando na futura produção de um material etnopedagógico que auxilie os licenciando e professores nas suas práticas.

\section{MATERIAL E MÉTODOS OU METODOLOGIA}

Esta investigação foi realizada com os parentes estudantes da UEFS que residiam ou não na Residência Indígena, mas que frequentam este espaço para manutenção de práticas culturais do seu povo e/ou como um espaço de articulação política do movimento estudantil indígena. Foram feitas entrevistas semi estruturadas no sentido de coletar informações sobre o uso das "músicas" nas práticas culturais dos povos, seus significados e funções, onde por meio das gravações, registramos alguns desses cantos/toantes/linhas/toré que foram transcritos para escrita musical.

As entrevistas foram realizadas em grupos, divididos de acordo com as etnias as quais os estudantes pertenciam e em dois momentos. Para o primeiro deles, elaboramos um roteiro onde buscamos compreender qual a importância e localização da música na cultura desses povos. No segundo momento pedimos que os parentes indígenas demonstrassem cantando algum canto/toante/linha/toré escolhida por eles para compor o material final. Para realizarmos essas entrevistas fizemos uso de um celular com aplicativo de gravador de áudio, câmera fotográfica, bloco de anotações e caneta.

\section{RESULTADOS E/OU DISCUSSÃO (ou Análise e discussão dos resultados)}

O processo de transmissão dos conhecimentos culturais/ancestrais dos nossos povos sempre foi por meio da oralidade; a forma como aprendemos acontece na vivência, observando os detentores dos saberes, na maioria das vezes nossos mais velhos, e experienciando no dia-a-dia junto com os parentes. A concepção de mundo para os indígenas difere-se das dos não-indígenas, a natureza é percebida como parte da gente, e as artes estão relacionadas a nossa espiritualidade ancestral. Assim, neste texto, a palavra música aparece com aspas por entender que para os povos aqui apresentados, nossas sonoridades são chamadas de cantos/toantes/linhas/toré, e a palavra música é tida como uma produção da cultura não-indígena ocidental.

[...] não se há uma palavra que se possa traduzir música [..] Toantes, linhas, cantos, cantigas são alguns dos nomes que podem ser equivalentes a este termo, algumas dessas "músicas" ou todas elas a depender do povo, podem ser chamadas de toré (Santos; 2018, p. 9-10).

Durante as entrevistas foi possível observar nas falas dos parentes a importância dos mais velhos para o povo, bem como uma pequena parte da grande riqueza étnico cultural das populações indígenas, pois somos povos com pontos que conversam entre si, mas, também, com muitas especificidades próprias de cada etnia. Nessa perspectiva, Santos (2017) diz que os povos indígenas, "se diferenciam em aspectos culturais, sociais, espirituais, entre outros, não sendo possível afirmar que existe a cultura e a história indígena, mas que há cultura(s) e história(s) indígenas" (SANTOS; 2017, p. 18), evidenciando que não é possível generalizar as questões dos povos originários do Brasil. Percebemos também o quanto as "músicas" são essenciais na estrutura social dos nossos povos, tendo em vista sua ligação com a nossa espiritualidade, destacando seu lugar no sagrado. O Toré aparece como elemento diacrítico dos indígenas desta região, estando presente em todos os povos indígenas do Nordeste embora de forma diferente como 
apresenta Santos (2017), o toré "em algumas etnias, é uma dança, em detrimento a outras, que o concebem como um ritual com caráter mais religioso" (SANTOS; 2017, p. 18). Algo que nos chamou atenção nesta pesquisa foi descobrir que um mesmo canto/toante/linha/toré pode está presente em várias etnias, mesmo que aconteça de forma diferente, com pequenas mudanças na melodia, no ritmo ou na letra, o que nos fez refletir sobre as semelhanças históricas e culturais das etnias que sempre tiveram fortes ligações desde o início da invasão dos nossos territórios, onde as trocas de saberes fortaleceram culturalmente e espiritualmente nosso ser indígena.

As "músicas" trazem elementos específicos de cada povo, como lugares sagrados a exemplo da Serra Umã dos Atikum, a Serrota para os Pankararé, e o Rio São Francisco para nós Tuxá, são lugares de força e resistência para nossos povos. Destaco as funções dessas músicas para cada povo, o toante Pankararu que registramos, por exemplo, é executado em um momento específico do ano dentro de um ritual guiado pela safra do fruto imbu neste povo. As melodias são bastante repetitivas e pequenas, mas não tiram a beleza e força dessas "músicas", que em seu contexto natural são executadas por horas, pois não é apenas o elemento sonoro que se é evidenciado nestes momentos, estão ligados a outros fatores, como dança, comida, gestos, objetos, pintura etc.

\section{CONSIDERAÇÕES FINAIS}

A música nas culturas indígenas aparecem como um elemento importante na estrutura social dos povos originários cantada ao som de maracás (instrumento utilizado por todos os povos participantes da pesquisa) sendo uma das formas de nos conectarmos com o sagrado e nos fortalecermos espiritualmente.

É imprescindível que cada vez mais nossos conhecimentos culturais sejam apresentados à academia, no sentido de mostrarmos para a sociedade não indígena as realidades às quais pertencemos, a partir das nossas perspectivas, e esta pesquisa possibilita essa aproximação, pois deixamos registrado e organizado como resultado um material construído a partir do que consideramos importante, podendo vir a ser usado nas escolas por profissionais em seu trabalho, disseminando o conhecimento sobre nossas culturas, contribuindo na desmistificação dos estereótipos e discursos que diariamente tentam negar nossas identidades.

\section{REFERÊNCIAS}

INSTITUTO BRASILEIRO DE GEOGRAFIA E ESTATÍSTICA (IBGE). População rural e urbana Indígenas no Brasil. BRASIL. Rio de Janeiro: IBGE, 2010.

BRASIL. Lei. 11.645/2008. No ensino médio públicos e privados, torna-se obrigatório o estudo da história e cultura afro-brasileira e indígena.

SANTOS, Andeson Cleomar dos. A formação do licenciando em Música na perspectiva da diversidade cultural. Monografia (Licenciatura em Música) departamento de Letras e Artes, Universidade Estadual de Feira de Santana, 2017.

SANTOS, Andeson Cleomar dos. Reafirmação do ser indígena: toantes, linhas e cantos na residência indígena da Universidade Estadual de Feira de Santana. Monografia (Especialização em Educação Musical) - Centro Universitário Claretiano, Feira de Santana-BA, 2018. 